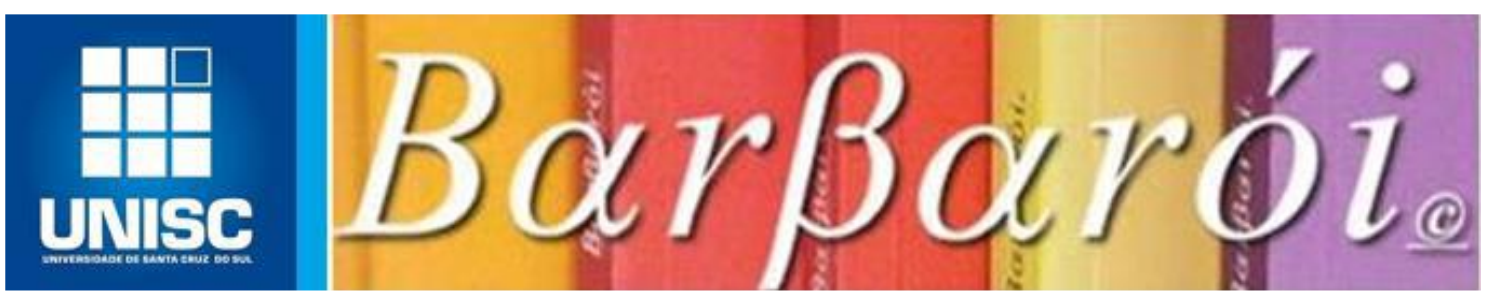

\title{
A PRODUÇÃO CIENTÍFICA DO SERVIÇO SOCIAL NA QUESTÃO DO SUICÍDIO
}

\section{DOI: http://dx.doi.org/10.17058/barbaroi.v0i0.13045}

\author{
$*$ \\ Francisco Elenilton Rodrigues do Nascimento \\ Universidade Federal do Ceará - UFC - Brasil \\ Maria Graça Fonseca Rocha \\ Hospital Universitário Walter Cantídio - HUWC-UFC - Brasil \\ Ana Paula de Lima Silva \\ Hospital Universitário Walter Cantídio - HUWC-UFC - Brasil

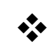

\section{Resumo}

O presente artigo é parte de uma pesquisa de abordagem qualitativa, de natureza aplicada, com objetivo exploratório e descritivo, constituindo-se da revisão bibliográfica narrativa, realizada no sentido de identificar e analisar a produção científica do Serviço Social sobre a temática do suicídio, apresentado ainda um breve relato da atuação profissional do/a assistente social no programa de prevenção ao suicídio, do hospital universitário da cidade de Fortaleza/CE, como contraponto às formas de atuação do assistente social identificadas na análise. Apontamos como resultados a baixa produtividade científica dos/as assistentes sociais sobre o tema do suicídio configurando-se como uma lacuna na literatura e a urgência de apropriação dessa temática a fim de ampliar o arcabouço teórico metodológico visando a relação da questão social e o suicídio configurando a emergência de novas formas de atuação e dos processos de trabalho.

Palavras-chaves: Serviço Social; Suicídio; Conhecimento; Prática Profissional

\section{Introdução}

As causas externas ${ }^{1}$ de morte são algo que nos deparamos cotidianamente, apresentando-se das mais diversas formas em nossa vida, tendo relação direta com o contexto de violência urbana - homicídio, latrocínio, agressões -, catástrofes naturais - deslizamentos,

\footnotetext{
1 “As causas externas são traumatismos, lesões ou quaisquer outros agravos à saúde - intencionais ou não - de início súbito e como consequência imediata de violência ou outra causa exógena. Neste grupo, incluem-se as lesões provocadas por eventos no transporte, homicídios, agressões, quedas, afogamentos, envenenamentos, suicídios, queimaduras, lesões por deslizamento ou enchente, e outras ocorrências provocadas por circunstâncias ambientais (mecânica, química, térmica, energia elétrica e/ou radiação)" (GONZAGA et al. 2012).
}

Barbarói, Santa Cruz do Sul, n.54, p.<102-118>, jul./dez. 2019 
desmoronamentos, inundações, furacões, terremotos -, e situações adversas - acidentes de trânsito, envenenamento, afogamento, queimadura, entre outras.

Deste modo, tais contextos não oriundos de situações ditas como "naturais" - mortes em decorrência da falência de órgãos ou óbitos advindos de adoecimentos - vem ganhando destaque no cenário nacional, como problema social e de saúde pública, demandando da agenda do Estado, ações para o seu enfrentamento.

Dentre as causas externas de morte destaca-se o fenômeno do suicídio, que apresenta um número crescente de vítimas em todo o mundo, sendo, no entanto, uma temática perpassada por tabu e preconceito - gerando temor ao falar no assunto e distanciamento da discussão, restrita apenas ao campo profissional.

Pesquisa da Organização das Nações Unidas (ONU, 2014) aponta que no ano de 2012, as mortes por suicídio, em todo o mundo, atingiram aproximadamente 800 mil pessoas. O Brasil ocupa a $8^{\mathrm{a}}$. posição no ranking mundial, registrando um quantitativo de 11 mil mortes ao ano. No ranking nacional o estado do Ceará ocupa o $5^{\circ}$ lugar, com 533 casos de suicídio no ano de 2015, sendo superado somente pelo estado de São Paulo (2.058 casos), Minas Gerais (1.279 casos), Rio Grande do Sul (938 casos) e Santa Catarina (630 casos), conforme o $10^{\circ}$ Anuário de Segurança Pública, divulgado no ano de 2016 pelo Fórum Brasileiro de Segurança Pública (JORNAL O Povo, 2016).

Dados do $1^{\circ}$. Boletim Epidemiológico de Tentativas e Óbitos por Suicídio no Brasil, conforme o Jornal Diário do Nordeste (MADEIRA, 2017), apontam que no período de 2011 a 2015 o estado do Ceará registrou 2.957 casos de suicídio, o que daria uma média de 591,4 casos de suicídio por ano. No entanto, acredita-se que o número de tentativas/óbitos é maior em comparação aos declarados nas estatísticas, devido às subnotificações das causas de mortes, camuflando a real magnitude do fenômeno.

Apesar de ser um tema de âmbito da Saúde Mental, de domínio da Psiquiatria e Psicologia, o suicídio apresenta-se como campo de intervenção do Serviço Social que, conforme Veloso et al (2017), é solicitado para intervir nas diversas expressões da questão social e suas interfaces com o fenômeno da "loucura" e sua manifestação por meio do suicídio ou violência auto infligida. A intervenção se confirma no acesso às informações, na mediação de conflitos, no resgate e fortalecimento dos vínculos familiares e comunitários, e na garantia de direitos.

Percebemos, então, que o tema suicídio, embora amplamente debatido na área do psiquismo, ainda é inexaurível em abordagens, estudos, análises e compreensões, principalmente quando olhamos, não somente para o "aparente desejo de morte", mas para as Barbarói, Santa Cruz do Sul, n.54, p.<102-118>,jul./dez. 2019 
diversas questões que perpassam ou estruturam esse sentimento. Essa compreensão nos impulsionou à abordagem do tema no trabalho de conclusão do Programa de Residência Multiprofissional com ênfase em Saúde Mental na cidade de Fortaleza/CE, cursado entre os anos de 2017 a 2019.

Dessa forma, apresentamos como um dos objetivos, que resultou neste artigo, identificar e analisar a produção científica do Serviço Social sobre o tema do suicídio, fazendo um contraponto das intervenções do assistente social identificadas na análise, com a intervenção desse profissional no programa de prevenção ao suicídio, do Hospital Universitário Walter Cantídio, da Universidade Federal do Ceará, denominado PRAVIDA - Programa de Apoio à Vida.

O material analisado foi extraído de um resgate de publicações de periódicos, e de programas de pós-graduação na modalidade stricto sensu, pesquisado em sites próprios, e no Google. Como resultado, esperamos provocar nos profissionais de Serviço Social uma reflexão acerca da produção científica sobre o tema, trazendo para a discussão, o suicídio como expressão da questão social, a partir da visão da integralidade do sujeito e das suas relações e vínculos familiares e sociais, fomentado um incremento no volume da produção teórica em matéria de Serviço Social.

\section{O suicídio como um problema social: a produção do conhecimento e a análise do problema}

Entendemos que a compreensão do suicídio como fenômeno social se processa a partir da análise das teorias sociais acerca do fenômeno, buscando a identificação das formas de intervenção do/da assistente social no atendimento a pacientes e familiares envolvidos no contexto do suicídio, promovendo a reflexão sobre a contribuição do Serviço Social na produção de conhecimento.

Conforme Tureki (1999 apud Elsing, 2009, p. 54) o uso da palavra suicídio foi mencionada pela primeira vez por Desfontaines, em 1737, e significa a morte intencional e auto infligida - um desejo exacerbado que a pessoa tem em escapar de uma situação estressante e de um sofrimento intenso, tirando a própria vida. Assim, o suicídio é considerado como "ato deliberado executado pelo próprio indivíduo, cuja intenção seja a morte, de forma consciente e intencional, mesmo que ambivalente, usando um meio que ele acredita ser letal" (ABP, 2014); e apresenta múltiplas causas para o seu cometimento - seja por situações relacionadas aos adoecimentos psíquicos/transtornos mentais e/ou o contexto social. 
Nesse sentido, Botega (2015) menciona os fatores de risco que possam influir no suicídio, tais como situações de tentativas prévias; o acometimento de alguma doença/transtorno mental; a presença de sentimentos de desesperança, desespero, desamparo; a faixa etária ${ }^{2}$; o gênero ${ }^{3}$; o diagnóstico de doenças crônicas e/ou severas não psiquiátricas; o histórico familiar e os fatores sociais.

Tais situações nos levam a compreender o fenômeno do suicídio, da violência autoprovocada e/ou auto infligida ${ }^{4}$, para além de uma dimensão estritamente biológica focada em patologias, em especial, de caráter psíquico, mas nas intervenções do contexto social e das relações que dele emergem como promotora deste tipo de comportamento. Bravo (2013) nos diz que

\begin{abstract}
a morbidade e a mortalidade ocorrem de maneira diferenciada em virtude da forma de inserção das classes no processo produtivo, acarretando diversificações nas oportunidades de consumo. Em decorrência, a vivência da morte e os problemas de doença nas classes trabalhadoras são maiores do que as frações ligadas ao capital, pois os desequilíbrios do processo saúde-doença acometem muito mais as frações ligadas ao trabalho (...) (p. 26).
\end{abstract}

Diante disso, acreditamos que por mais que o suicídio esteja circunscrito no espaço subjetivo sua materialidade na vida social apresenta-se de modo diversificado para aqueles que detém meios e recursos de acesso à saúde, à alimentação, à moradia, ao lazer e as demais instâncias para garantia do básico da qualidade de vida.

Na teoria sociológica, Durkheim (1977) faz a sua análise a partir do fato social $^{5}$ e compreende o suicídio como um fenômeno natural e que está presente em todas as sociedades, variando suas proporções de ocorrência. Além disso, aponta que quanto mais o indivíduo possui laços fortes de solidariedade a nível social, menor será a probabilidade de suicídio. Esse pensamento aparentemente coloca o fenômeno do suicídio no nível microssocial, de ordem psíquica, individual, isolada, subjetiva e, porque não dizer, de relevância pontual.

\footnotetext{
2 “O suicídio em jovens aumentou em todo o mundo nas últimas décadas e também no Brasil, representando a terceira principal causa de morte nessa faixa etária no país [...]. O suicídio também é elevado entre os idosos, devido a fatores como: perda de parentes, sobretudo do cônjuge; solidão; existência de enfermidades degenerativas e dolorosas; sensação de estar dando muito trabalho à família e ser um peso morto para os outros" (ABP, 2014, p. 18-19).

3 “'Os óbitos por suicídio são em torno de três vezes maiores entre os homens do que entre mulheres. Inversamente, as tentativas de suicídio são, em média, três vezes mais frequentes entre as mulheres (ABP, 2014, p.19).

4 "Vale ressaltar que a definição clássica de violência autoinfligida apresenta-se como: 'todo caso de morte que resulte, direta ou indiretamente de um ato positivo ou negativo, praticado pela própria vítima, sabedora de que poderia produzir esse resultado'. Assim, violência autoinfligida é um ato consciente e autodestrutivo, que pode ser compreendido como uma enfermidade multidimensional" (CAMARGO, 2011, p. 101).

5 "É fato social toda maneira de agir fixa ou não, suscetível de exercer sobre o indivíduo uma coerção exterior ou, ainda, que é geral em uma determinada sociedade, apresentando uma existência própria, independente das manifestações individuais. Os fatos sociais existem fora dos indivíduos, mas são interiorizados e passam a existir em suas consciências. São externos porque foram transmitidos socialmente aos indivíduos" (ALMEIDA, 2014).
} 
Para Marx (2006), o suicídio expressa de modo latente e significativo a fuga deste mundo perpassado pelos desafios de produzir e reproduzir a vida da classe trabalhadora, malefícios a nível psíquico das investidas do mercado de consumo e do sistema capitalista. Por isso, nos diz que "o suicídio não é mais do que um entre os mil e um sintomas da luta geral” (p. 29). Na teoria de Marx, os acirramentos das desigualdades sociais são advindos da contradição do capital e do trabalho, devido a produção da riqueza social e simbólica construir-se de modo coletivo, enquanto a sua apropriação apresenta-se de modo particularizado por um grupo/classe específica. E, assim, as demandas da população afetada pela divisão capital/trabalho exigem a atuação do Estado, que passa a oferecer uma intervenção tecnificada, num contexto em que a caridade e a filantropia das instituições religiosas não conseguem dar conta dos problemas sociais.

Nesse sentido,

O Serviço Social, como prática profissional, surge no final do século XIX e início do século XX, quando o capitalismo consolida sua hegemonia a nível mundial, sendo caracterizado como capitalismo monopolista. Aparece como um dos mecanismos para atender aos efeitos das contradições criadas pelo novo estágio desse sistema de produção, pois as formas adotadas pelos pioneiros da assistência, baseado na caridade e na filantropia, eram insuficientes para o controle dos problemas sociais, com o aviltamento da pobreza, ocasionado pela exploração intensiva do trabalho (BELFIORE et al, 1985 apud BRAVO, 2013, p. 21).

Essas reflexões nos impulsionam a observar o suicídio como um fenômeno macrossocial, fazendo correlações com as contradições da ordem do capital e os adoecimentos advindos do modo de como a vida social encontra-se organizada e estruturada, compreendendo que devido este cenário antagônico, surge como resultado os problemas de ordem social e as sequelas da exploração do trabalho, que, de algum modo, engendra adoecimentos físicos e psíquicos à classe trabalhadora (BRAVO, 2013).

Essa conjuntura nos dá materialidade como categoria profissional na atuação direta às manifestações da questão social ${ }^{6}$, tendo como pano de fundo as relações no cotidiano - espaço por excelência onde se apresentam as lutas e as contradições da vida social - e na operacionalização das políticas públicas e sociais. E sendo o suicídio um fenômeno do âmbito social, demanda urgente atuação e intervenção dos profissionais de Serviço Social - categoria que se depara constantemente com as diversas situações de opressão, negligência, abandono, violência, pobreza e os mais variados contextos.

\footnotetext{
6 "A Questão Social é apreendida como um conjunto das expressões das desigualdades da sociedade capitalista madura, que tem uma raiz comum: a produção social é cada vez mais coletiva, o trabalho torna-se mais amplamente social, enquanto a apropriação dos seus frutos mantém-se privada, monopolizada por uma parte da sociedade" (IAMAMOTO, 1998, p. 27).
}

Barbarói, Santa Cruz do Sul, n.54, p.<102-118>,jul./dez. 2019 


\subsection{A produção científica}

Compreendendo que a tríade das dimensões teórico-metodológica, ético-política e técnico-operativa são indissociáveis ao fazer profissional, ressaltamos a importância da produção científica em matéria de interesse do Serviço Social. Assim, realizamos uma pesquisa bibliográfica, a fim de identificar e analisar o material teórico produzido por assistentes sociais sobre o tema do suicídio ou a ele relacionado.

Foram pesquisados três periódicos relevantes em matéria de Serviço Social, escolhidos a partir do nível Qualis, entre A1 e B $1^{7}$, considerando-se a relevância científica para a categoria profissional e comunidade acadêmica, sendo estes: Temporalis - Revista da Associação Brasileira de Ensino e Pesquisa em Serviço Social (ABEPSS); Serviço Social e Sociedade Editora Cortez, e a Katálysis, vinculada à Universidade Federal do Rio Grande do Sul (UFRGS), nos respectivos sites. Assim, identificamos a produção, no período de 2010 a 2017 a partir dos temas saúde, saúde mental, e suicídio, conforme as análises e tabela abaixo.

Na revista Katálysis foram identificados 22 artigos relacionados à saúde nas suas mais diversas abordagens. Destes, 3 correspondiam à saúde mental e somente 1 fazia referência ao suicídio. A revista Temporalis encontramos 6 artigos sobre saúde e destes somente 1 de saúde mental. No entanto, nenhum com referência ao suicídio - fato que também se repete na Revista Serviço Social \& Sociedade com 15 artigos sobre saúde, sendo 6 sobre saúde mental e nenhum sobre suicídio.

No tocante ao Programa de Pós-Graduação, optamos pelo Mestrado Acadêmico em Serviço Social, Trabalho e Questão Social (MASS) vinculado à Universidade Estadual do Ceará (UECE), fazendo um levantamento da produção das turmas de 2012 a 2015, disponíveis no site da instituição, identificando 41 dissertações. Destas, somente 3 estavam relacionados a temática de "saúde" e 2 a "saúde mental". O tema do suicídio não foi abordado em nenhuma das dissertações.

Tínhamos também o desejo de incluir os encontros, congressos e simpósios significativos para a categoria profissional como o Encontro Nacional de Pesquisadoras/res em Serviço Social - ENPESS e o Congresso Brasileiro de Assistentes Sociais - CBAS, porém, devido à dificuldade de acesso aos anais das edições anteriores, decidimos não os incluir na pesquisa.

\footnotetext{
${ }^{7}$ Qualis-Periódico é um sistema usado para classificar e avaliar os artigos publicados em periódicos científicos. Podendo ser classificados nos indicativos de qualidade A1 - nível mais elevado, A2, B1, B2, B3 e C - com peso zero.
} 
No sentido de obter mais material para a análise proposta, realizamos uma busca de forma aleatória, através do site Google, pelas produções de trabalhos de conclusão de curso, dissertações e teses, a fim de discutir como a categoria profissional vem compreendendo o fenômeno do suicídio na realidade social e como apresenta-se a prática profissional do/da assistente social nos espaços sócio ocupacionais onde é demandada a sua intervenção, sendo pesquisados os trabalhos a partir dos temas: "Serviço Social e o Suicídio", "Serviço Social e a Violência Auto infligida", e "Serviço Social e a Violência Autoprovocada", sendo identificados dois trabalhos de conclusão de curso e uma dissertação de mestrado que versavam sobre o suicídio.

Verifica-se, portanto, que o Serviço Social apresenta uma baixa produção teórica nos temas relacionados ao suicídio, observando-se a necessidade de incrementar pesquisas que conduzam à produção do conhecimento, no sentido de promover o desenvolvimento e fortalecimento do arcabouço teórico da categoria profissional sobre a temática, e servir como subsidio de apoio e referência para os/as assistentes sociais que atuam em espaços sócio ocupacionais que lidam diretamente com pessoas em crise suicida - Centro de Atenção Psicossocial/CAPS, Unidades de Pronto Atendimento/UPA, Hospitais de Urgência e Emergência, Hospitais Psiquiátricos, Hospitais Gerais de atendimento ambulatorial de Saúde Mental - e nas outras políticas setoriais nas quais possam se deparar com o fenômeno.

É preciso também compreender o porquê dessa baixa produtividade, uma vez que a atuação do/da assistente social se torna cada vez mais relevante em programas de prevenção ao suicídio e nos diversos equipamentos de saúde ante aos bens, serviços e direitos sociais, conforme destacado nos trabalhos selecionados.

\subsection{A análise do problema}

Neste subitem apresentamos a produção teórica identificada na pesquisa bibliográfica, trazendo para análise o pensamento das autoras sobre o suicídio e atuação profissional, fazendo um contraponto com a prática profissional do assistente social no Programa de Prevenção ao Suicídio - PRAVIDA, desenvolvido no Hospital Universitário Walter Cantídio - HUWC.

Identificamos 4 trabalhos, sendo um artigo científico; dois trabalhos de conclusão de curso, e uma dissertação de mestrado, analisados a partir do pensamento central de cada autora, organizados por ordem de análise, sendo estes:

1. La Prevención del Suicídio Juvenil: Entre la Enunciación y la Acción - Artigo científico, de Elsa Viviana Barrón e Claudia Sandra Krmpotic, publicado pela Revista Katálysis, 2016;

Barbarói, Santa Cruz do Sul, n.54, p.<102-118>, jul./dez. 2019 
2. A Intervenção do Assistente Social no Atendimento de Emergência do HU/UFSC às Tentativas de Suicídio - Trabalho de Conclusão de Curso, de Iara da Silva Pinheiro, pela Universidade Federal de Santa Catarina (UFSC), 2008;

3. Suicídio e Alienação: A Vivência Cotidiana da Desigualdade e da Exclusão Social - Dissertação de mestrado, de Sandra Regina Smith Neves, pela Universidade Federal do Pará (UFPA), 2007;

4. O Serviço Social no Atendimento ao Usuário Vítima de Tentativa de Suicídio: Desafios e Possibilidades - Trabalho de Conclusão de Curso, de Aline Dias Santos, Luiza Queiroz do Nascimento, Tatiana Paiva Rosa, pela Escola Superior de Ciências da Santa Casa de Misericórdia de Vitória, 2016.

No trabalho de Barrón \& Krmpotic (2016, p. 43) são estudadas as estratégias argumentativas para explicar o cometimento de suicídio pela população juvenil levando em consideração as características do fenômeno e as possíveis formas de prevenção. Para tanto, as autoras debruçam-se sobre a leitura e análise de conteúdo das publicações de artigos, teses de doutorado e capítulos de livros por sociólogos, teólogos, filósofos e profissionais de saúde que produziram sobre a temática do suicídio em geral e juvenil, em particular, entre os anos de 1990 e 2011, que foram coletados em bibliotecas e bancos de dados on-line (REDALYC, SCIELO, UNAM, ALAP, OMS, OPAS), bem como em bibliotecas dando destaque a da Cidade de Buenos Aires, Argentina.

As autoras, apesar de indicarem 3 noções chaves para a compreensão do suicídio como problema social, sendo estas: fatores de risco, doença mental e morte, se debruçam sobre os fatores de risco como lógica preventiva na finalidade de compreender o suicídio numa dinâmica ampla e macrossocial. Nesse sentido, referem que

[...] para las profesiones de cuidado en general, y para el Trabajador Social en
particular, el suicidio juvenil - sea en la ideación, el intento o la consumación -
presenta nuevas exigencias en materia de diagnóstico social fundado, como respecto
del reconocimiento de la interfaz socio-legal presente en estas situaciones que atañen
no sólo al protagonista, sino a sus cuidadores como al entorno socio-familiar más
amplio (BARRÓN \& KRMPOTIC, 2016, p. 44).

Ao abordar o contexto argentino, Sterfaty (2015) apud Barrón \& Krmpotic (2016), revela que a taxa de morte por suicídio aumentou de 1,5 por 100.000 habitantes em 1991 para 6,1 no ano de 2000. Já os dados oficiais contabilizam que entre os anos 2000 e 2007 morreram 44.829 jovens, com um média de 5.603 por ano e cerca de 15 por dia, dos quais 10 foram devido a causas evitáveis, enquanto entre 2 e 3 por suicídio (BARRÓN, 2015).

Numa revisão sobre a temática, as autoras desenvolvem as seguintes elucidações: 
i) el suicidio es um proceso que se inicia con una ideación, la muerte es premeditada, deliberada; ii) el suicidio es un acto que rompe con la racionalidad. En el origen del suicidio hay una decisión de poner fin a algo que difícilmente es la propia existencia del sujeto que muere; iii) los factores que llevan al suicidio se dividen en dos grandes grupos: predisponentes y desencadenantes. Estos últimos son siempre sociales. Por la profundidad de su impacto precipitan el pasaje al acto del suicidio, sin ser completamente responsables del suicidio. No obstante, se cree que sin la presencia de elementos predisponentes, aun con los mismos episodios desencadenantes, no se daría el suicidio consumado; iv) la familia tiene un rol protagónico en su desencadenamiento (familias inestables, abandónicas, violentas, extremadamente rígidas, ausentes; familias que no cuidan); y v) el ámbito educativo formal como la pertinencia a otros espacios de socialización informal, son efectivos en la prevención del suicidio (BARRÓN \& KRMPOTIC, 2016, p. 44-45).

Tais situações apresentadas são entendimentos também vivenciados nas ações profissionais e compreensões brasileiras sobre o fenômeno do suicídio frisando a relevância de problemas sociais como desencadeantes e impulsionadoras de ações contra a própria vida. $\mathrm{Na}$ análise das obras escolhidas por Barrón \& Krmpotic (2016), numa compreensão sociológica há uma expressiva produção em organismos internacionais como a Comissão Econômica para a América Latina e o Caribe - CEPAL, a Organização das Nações Unidas - ONU e a Organização Mundial de Saúde - OMS com elevada referência do trabalho do sociólogo Émile Durkehim como pioneiro do tema do suicídio. Já nos trabalhos no âmbito da saúde pública, apontam publicações relacionadas aos fatores de risco, sua identificação e mensuração.

Pinheiro (2008) aborda a experiência de estágio em Serviço Social na Emergência do Hospital Universitário de Santa Catarina - HU/UFSC, em atendimento a pacientes com história de tentativas de suicídio, e inicia sua análise conceituando a saúde mental não apenas como ausência de doença, mas um contexto de bem-estar físico, mental e social manifesto por meio do acesso as condições básicas de vida como liberdade, alimentação, transporte, habitação, educação, trabalho, renda, lazer, acesso à serviços de saúde e entre outros.

Em seguida, realiza um breve resgate histórico da política de saúde mental brasileira e da reforma psiquiátrica pautando o contexto das precárias condições de trabalho e de atendimento à população adoecida, referindo que até meados do século XVII, havia uma relação entre o suicídio e o homicídio, sendo ambos ação de ferir a vida. Desse modo, o ato de matarse encontrava-se no rol dos crimes $^{8}$ e sacrilégios, e os suicidas sem êxito eram condenados à pena de morte.

Também são abordadas nesse trabalho as contribuições de teoria sociológica sobre o tema, tendo como principais representantes Karl Marx e Émile Durkheim. Para Marx, segundo a autora, o suicídio seria uma manifestação da não "adequação" do sujeito às condições de

\footnotetext{
8 “As leis que vigoravam por volta do século XVII (especificamente, a ordenança em 1670) deixavam claro que o suicídio era um crime de 'lesa-majestade humana ou divina"” (PINHEIRO, 2008, p. 19).
}

Barbarói, Santa Cruz do Sul, n.54, p.<102-118>, jul./dez. 2019 
produção e reprodução de sua vida estando subjugado na dicotomia de explorador-explorado. Assim, na sua compreensão acerca do pensamento de Marx, a autora nos diz que ele

[...] se interessa pelo tema não tão somente pela própria questão do suicídio, mas sim como oportunidade de expor sua crítica radical da sociedade burguesa, ressaltando o modo de viver 'antinatural', sendo assim o suicídio um sintoma forte de uma sociedade adoecida, carente por transformações radicais” (PINHEIRO, 2008, p. 19).

Em relação à teoria de Émile Durkheim quanto ao tema suicídio, compreende que ele

[...] nos propõe analisar o suicídio como um fato social, isto é, deixar de entender o suicídio apenas como um fenômeno isolado e individual e observar os dados (sociais e culturais) que o fenômeno transmite, indicando que deve ser tratado de maneira coletiva, analisando primeiramente o todo, o conjunto. De acordo com seu conceito, o suicídio para Durkheim é produto de um profundo conflito estabelecido no meio social exterior ao indivíduo, sendo assim cada sociedade, de acordo com sua hipótese, teria uma tendência coletiva ao suicídio, sendo que as respostas para eles se encontrariam justamente no mundo exterior ao indivíduo" (PINHEIRO, 2008, p. 21).

Assim, conclui que tanto Marx quanto Durkheim partem do mesmo ponto de vista em que o suicídio se apresenta como uma ação resultante da realidade social externa ao indivíduo por meio de situação de extrema individuação em relação à um contexto social, pela relação da intensa ligação a valores coletivos ou mesmo resultante de situações de crise social na relação do sujeito com o mundo.

Pinheiro (2008) se refere ainda ao processo de fundação do Hospital Universitário da UFSC e sua organização institucional, assim como a inserção e atuação do Serviço Social sendo o seu público prioritário formado por

[...] adultos e crianças com baixa escolaridade, trabalhadores rurais e urbanos, desempregados, subempregados, aposentados, domésticos, migrantes entre outros. Essas pessoas procuram o Serviço Social para solicitar assistência em situações, problema ou auxílios concretos: alojamento, asilo, consultas, exames, alimentação, medicamentos, órtese, prótese, passagem, informações sobre o processo de internação, entre outros (PINHEIRO, 2008, p. 32).

Esse é o perfil das pessoas que cotidianamente solicitam a intervenção do/a assistente social para mediar o acesso à informação e às políticas públicas no intuito de assegurar os seus direitos. Pinheiro (2008) refere que o projeto de atuação na emergência iniciou no ano de 1996 onde são atendidas aproximadamente 300 pessoas por dia, sendo o atendimento organizado a partir das demandas que os indivíduos trazem ao equipamento de saúde onde são triadas por meio de classificação de risco que aquela situação vivenciada pode acarretar para a sua vida. Por isso,

[...] a classificação de risco, a partir da sistematização por cores que significariam a gravidade da situação, bem como, quanto tempo o paciente levaria para ser atendido. Nesta classificação de risco a cor vermelha é sinalizada para os casos mais graves, que devem ser atendidos com urgência, a cor amarela representa os casos que 
necessitam ser atendidos em até trinta minutos, e de cor verde, atendimento rápido até uma hora. A cor azul é utilizada para os casos que podem ser atendidos nas Unidades Básicas de Saúde, pois são casos menos graves (PINHEIRO, 2008, p. 38-39)

Para tanto, essa triagem das demandas e/ou "o acolhimento é antes de tudo, um instrumental de referência tanto de maneira geral para os profissionais da área da saúde, quanto para o assistente social que intervém na realidade do cotidiano de uma emergência hospitalar" (PINHEIRO, 2008, p. 38-39) auxiliando na organização e no desenvolvimento de ações resolutivas aos usuários da política pública de saúde.

Ainda segundo a autora, os atendimentos realizados na emergência do Hospital Universitário/UFSC são “[...] geralmente a partir das entrevistas, observações, relatórios, levantamentos de recursos, encaminhamentos, pareceres sociais, contatos institucionais, entre outros" e que "[...] a primeira etapa consiste na entrevista realizada no leito ou maca do usuário”, onde são coletados os dados iniciais (PINHEIRO, 2008, p 39).

A autora traz ainda uma breve contextualização do suicídio, e a família ante esse fenômeno, fazendo a análise de quatro, dentre os casos atendidos - todos do sexo feminino, com faixa etária superior a 30 anos de idade e com tentativas de suicídio por meio de ingestão de medicamentos psicoativos (antidepressivos e tranquilizantes). Em um dos casos houve também a ingestão de solda caustica; um caso com histórico de tentativa de suicídio anterior e outro com histórico de internação.

A pesquisa de conclusão de curso de graduação de Santos, Nascimento, e Rosa (2016) tem como objetivo central a intervenção do Serviço Social nas redes de atendimento referente aos casos de tentativas de suicídio. Nesse sentido, as autoras buscaram compreender o papel da profissão no atendimento às pessoas com ideação suicida, e quais os instrumentos e saberes próprio da categoria profissional na intervenção do problema.

A pesquisa acima mencionada "é descritiva com característica de abordagem qualitativa, com pesquisa bibliográfica, elaborada a partir de material já publicado, como livros, artigos, internet, etc" (SANTOS; NASCIMENTO; ROSA, 2016, p. 10). De início, as autoras apresentam brevemente os dados epidemiológicos das tentativas de suicídio no mundo. Em seguida, fazem alusão às referências de Marx e Durkheim para compreenderem a temática numa visão social e autores contemporâneos na área da Saúde Mental com foco nos sinais comportamentais. Por fim, apresentam brevemente a rede de atendimento psicossocial e a relação com outros equipamentos sociais (governamentais ou não) que possam auxiliar na abordagem. 
Nos trabalhos de Pinheiro (2008, p. 48) e Santos, Nascimento, e Rosa (2016, p. 21) encontramos semelhanças referente aos aportes teóricos das bibliografias já produzidas fazendo alusão aos clássicos de Marx e Durkheim e sobre as intervenções do Serviço Social ocorrendo de forma "muito raras" devido o profissional não atuar de forma plena nos processos de trabalho da equipe multiprofissional. Além disso, apontam a dificuldade de comunicação entre os profissionais da equipe de saúde ficando o Serviço Social voltado para ações focalizadas apenas nos aspectos relacionados à alta hospitalar do usuário (suporte familiar, transporte) e também em aspectos relacionados aos princípios básicos de dignidade humana (tais como roupa e cesta básica).

A partir desses argumentos, Santos, Nascimento, e Rosa (2016) justificam a baixa atuação do Serviço Social, ou uma atuação que ocorre em circunstâncias pontuais durante o processo de internação dos sujeitos atendidos por tentativa de suicídio. Por outro lado, a autora refere que

\begin{abstract}
os assistentes sociais que atuam em serviços de urgência e emergência nos hospitais públicos estão numa posição especial para participar do encaminhamento dos casos de tentativa de suicídio para a rede de prevenção e controle, assim como os familiares daqueles que suicidaram (p. 22-23) e (...) outro aspecto importante da atuação dos assistentes sociais é sua possibilidade de apoiar as pessoas próximas ao usuário que cometeu suicídio e têm suas vidas diretamente afetadas por isso, os "sobreviventes". Os assistentes sociais podem contribuir muito para a preparo, a orientação e o acompanhamento de grupos dos sobreviventes (p. 23).
\end{abstract}

Apesar de atuarmos diretamente com a temática do suicídio ou situações que a ele estejam correlacionadas, Santos, Nascimento, e Rosa (2016) constatam em sua pesquisa que a temática ainda não é vista nos estudos do Serviço Social deixando lacunas sobre o nosso olhar profissional ante o fenômeno e configurando-se uma carência na literatura.

Neves (2007) inicia o seu trabalho ressaltando a importância da produção de Durkheim e Marx sobre o suicídio; em seguida apresenta o processo de ocupação do território amapaense com suas peculiaridades históricas locais e da cidade do Amapá/AP e, por fim, a discussão da categoria família e os índices de suicídio no município.

Segundo a autora, pouco se pesquisa sobre a temática do suicídio no Brasil. Ela discute o assunto a partir das ocorrências de tal fenômeno na cidade do Macapá/AP durante os anos de 2001 a 2005, realizando uma correlação da temática com o pensamento marxista e marxiano evitando uma perspectiva individual e isolada do fenômeno. A coleta de dados ${ }^{9}$ foi realizada

\footnotetext{
9 "Esses dados foram obtidos nos arquivos da Polícia Técnica e Científica, Assessoria Técnica em Estatística SEJUSP, e arquivo pessoal de José Cardoso Neto. Os dados sobre tentativas de suicídio, foram informados por meio do Arquivo Médico do Hospital de Emergências de Macapá e Serviço de Psicologia do mesmo hospital. As ocorrências de suicídio no período citado somam 137 casos, destes foram selecionadas 20 famílias para realização Barbarói, Santa Cruz do Sul, n.54, p.<102-118>,jul./dez. 2019
} 
por meio de observação, formulários, entrevistas com familiares, vizinhos e amigos das vítimas, e pessoas que vivenciaram a experiência de tentativa de suicídio.

A autora nos revela que a sua proposta de trabalho é um esforço de ir além das explicações ancoradas em motivações individuais que levam ao suicídio, mas investigar e compreender o fenômeno a partir do desenvolvimento da cidade de Macapá. Para tanto, os seus objetivos da pesquisa são

Entender o suicídio em uma cidade com as peculiaridades de Macapá encravada na região amazônica; examinar a relação existente entre o processo migratório recente, $o$ crescimento populacional e a taxa de suicídios registrada na cidade; e colaborar com estudos para a formulação de políticas de prevenção ao suicídio (NEVES, 2007, p. 17).

Inicialmente, a autora considera e relaciona a ocorrência do suicídio ao processo de

[...] urbanização intensa e acelerada da cidade de Macapá, o processo migratório e o consequente crescimento da população urbana, a forma como o trabalho é organizado, afetam a subjetividade, as relações do indivíduo com o sentido da vida desenvolvendo várias formas de violência entre estas o suicídio (NEVES, 2007, p. 17).

O cotidiano é o espaço onde as desigualdades e as contradições da vida social ganham forma e as violências manifestam-se nos sujeitos. É nesse mesmo espaço que a atuação profissional, em especial a do Serviço Social, ganha materialidade, e onde intervimos de modo real e concreto. Por isso, a autora nos diz que

\begin{abstract}
a cotidianidade consiste no espaço de satisfação das necessidades essenciais do indivíduo. Desde modo a estrutura material da vida cotidiana, corresponderia a uma dada estrutura psíquica, sendo o comportamento uma das expressões do mundo psíquico. Por tanto, o psiquismo, a subjetividade, se desenvolve ao longo da vida e não pertence a natureza do homem, mas reflete a condição econômica, social, e cultural em que vivem os homens (NEVES, 2007, p. 19)
\end{abstract}

Portanto, ao analisarmos o estudo dessa autora compreendemos que o psiquismo e a subjetividade são frutos de uma cotidianidade incorporando valores sociais, éticos e culturais já existentes na vida do homem.

Observamos na análise do material apresentado que a atuação do Serviço Social não apresenta uma relação mais aprofundada com o fenômeno do suicídio, configurando-se de forma usual, prestando orientação e viabilizando o acesso a direitos sociais e benefícios assistenciais. Assim, no contraponto da análise teórica, trazemos como contribuição para a discussão da categoria, as observações de um fazer profissional a partir de um olhar mais ampliado sobre o fenômeno, durante nosso período de Residência Multiprofissional em Saúde

da entrevista, um total de $15 \%$ dos casos. A coleta de dados ocorreu entre agosto de 2006 e janeiro de 2007, e abarcou além da coleta nos locais anteriormente referidos, visitas as residências das famílias para realização das entrevistas" (NEVES, 2007, p. 19).

Barbarói, Santa Cruz do Sul, n.54, p.<102-118>, jul./dez. 2019 
Mental do Hospital Universitário Walter Cantídio, da Universidade Federal do Ceará, atuando no Programa PRAVIDA.

O Programa PRAVIDA tem como fator importante para o cuidado terapêutico de pacientes com ideação suicida, o acompanhamento de familiares e/ou responsáveis - presença imprescindível no processo de tratamento, pelo fato de se transmitir orientações sobre os cuidados com objetos perfuro-cortantes, substâncias nocivas à saúde existentes em casa e evitar contextos que possam dispor de condições para o cometimento da prática suicida.

No tocante a atuação do Serviço Social, primamos pelo fortalecimento dos vínculos familiares, realizando uma intervenção individual, com cada familiar/acompanhante para compreender o contexto social, as relações e vínculos familiares/afetivos, identificando situações preexistentes ou que possam emergir durante o atendimento, visando uma intervenção ampliada para além do adoecimento psíquico levando em consideração as diversas manifestações da questão social que se apresentam no contexto familiar, identificando as referências do indivíduo e da família, além de identificar a rede de apoio e os equipamentos sociais existentes.

\section{Conclusão}

A partir da análise da produção literária e atuação do/da assistente social no campo da saúde mental, com foco no suicídio, entendemos que esse fenômeno precisa ser compreendido a partir do viés multidisciplinar superando uma abordagem isolada e individual. Para tanto, urge a participação das mais variadas profissões do âmbito da Saúde, das Ciências Sociais e Humanas Aplicadas e tantas outras que possam somar nessa ação de cuidado.

Apesar do Serviço Social ser uma profissão consolidada na cultura organizacional de diversas instituições, atuando nas manifestações da questão social e sendo convocado para dar respostas em várias situações de emergência, calamidade, negligência, violência e privação de direitos, a temática do suicídio ainda permanece invisível nas produções acadêmicas - seja por meio de artigos em periódicos e na pós-graduação na modalidade stricto senso.

Consideramos que o reduzido número de publicações acerca do suicídio, por parte do Serviço Social não ocorre por desconhecimento de causa ou ausência de contato empírico com o fenômeno, mas pelas limitações corriqueiras que perpassam ao contexto de morte, neste caso em "tirar a vida", no qual nos limitamos em atuações burocráticas e tecnicistas.

Observamos, nos trabalhos analisados, que não há uma referência específica sobre "as diversas formas de atuação" do/a assistente social, limitando-se a referenciarem o caráter burocrático do fazer profissional frente ao suicídio. Por isso, compreendermos ser necessário Barbarói, Santa Cruz do Sul, n.54, p.<102-118>,jul./dez. 2019 
para o/a assistente social que atua nessa área, ampliar o seu campo de visão sobre o suicídio, adentrando um pouco o ambiente da Psicologia e da Psiquiatria a fim de compreender as nuances e significações dos problemas sociais enfrentados pelo indivíduo com pensamentos ou tentativas de tirar a própria vida, para uma intervenção mais consolidada dentro da equipe multidisciplinar, instigando o profissional a empreender pesquisas que possam revelar o caráter social do fenômeno suicídio, incrementando a produção do Serviço Social nessa temática.

\title{
THE SCIENTIFIC PRODUCTION OF SOCIAL WORK IN SUICIDE
}

\begin{abstract}
This article is part of a research of qualitative approach, of applied nature, with exploratory and descriptive objective, constituting of the narrative bibliographical revision, realized in order to identify and analyze the scientific production of Social Work on the theme of Suicide, a brief account of the social worker 's professional performance in the suicide prevention program of the university hospital of the city of Fortaleza/CE is presented, as a counterpoint to the forms of work of the social worker identified in the analysis. As a result we point out the low scientific productivity of social workers on the subject of suicide configuring as a gap in the literature and the urgency of appropriation of this theme in order to broaden the methodological theoretical framework aiming at the relation of the social issue and suicide, configuring the emergence of new forms of action and work processes.
\end{abstract}

Keywords: Social Service; Suicide; Knowledge; Professional Practice

\section{PRODUCCIÓN CIENTÍFICA DEL SERVICIO SOCIAL EN SUICIDIO}

\section{Resumen}

Este artículo forma parte de una investigación de enfoque cualitativo, de naturaleza aplicada, con objetivo exploratorio y descriptivo, que constituye la revisión bibliográfica narrativa, realizada con el fin de identificar y analizar la producción científica del Trabajo Social sobre el tema de Suicidio, se presenta una breve reseña del desempeño profesional del trabajador social en el programa de prevención del suicidio del hospital universitario de la ciudad de Fortaleza/CE, como contrapunto a las formas de trabajo del trabajador social identificadas en el análisis. Como resultado, señalamos la baja productividad científica de los trabajadores sociales en el tema del suicidio que se configura como una brecha en la literatura y la urgencia de apropiación de este tema para ampliar el marco teórico metodológico que apunta a la relación de la cuestión social y el suicidio, configurando la aparición de nuevas formas de acción y procesos de trabajo.

Palabras Clave: Servicio Social; Suicidio; Conocimiento; Práctica Profesional

\section{REFERÊNCIAS}

ASSOCIAÇÃO BRASILEIRA DE PSIQUIATRIA/ABP. Suicídio: informando para prevenir. Conselho Federal de Medicina/CFM. 2014, 52p.

BARRÓN, E. V.; KRMPOTIC, C. S. La prvención del suicídio juvenil: entre la enunciación y la acción. R. Katálysis, Florianópolis, v. 19, n. 1, p. 43-52, jan./jun. 2016. Disponível em: 
https://periodicos.ufsc.br/index.php/katalysis/article/view/40233/31963. Acesso em 28 mai. 2018.

BOTEGA, N. J. Crise suicida: avaliação e manejo. Porto Alegre: Artmed, 2015.

CAMARGO, F. C. et al. Violência autoinfligida e anos potenciais de vida perdidos em Minas Gerais, Brasil. Texto Contexto Enferm, Florianópolis, 2011; 20 (Esp): 100-7. Disponível em: http://www.scielo.br/pdf/tce/v20nspe/v20nspea13.pdf. Acesso em 24 mai. 2018.

DURKHEIM, É. O suicídio. Estudo sociológico. Trad. de Luz Cary, Margarida Garrido e J.Vasconcelos Esteves. 2. ed. Lisboa: Editorial Presença, 1977.

ELSING, F. Suicídio: Uma revisão de Literatura. In Escudeiro, A.(Org.) Reflexões sobre Morte e Perda. Fortaleza, L.C. Gráfica e Editora, 2009.

GONZAGA, Ricardo Alessandro Teixeira et al. Avaliação da mortalidade por causas externas. Rev. Col. Bras. Cir., Rio de Janeiro, v. 39, n. 4, p. 263-267, ago. 2012. Disponível em http://www.scielo.br/scielo.php?script=sci_arttext\&pid=S010069912012000400004\&lng=en\&nrm=iso. Acesso em 10 jan. 2018.

JORNAL O POVO. Ceará é o $5^{\circ}$ estado em número de suicídios. Disponível em https://www.opovo.com.br/noticias/fortaleza/2016/11/ceara-e-o-5-estado-em-numero-desuicidios.html. Acesso em 29 out. 2017.

MADEIRA. V. JORNAL DIÁRIO DO NORDESTE. Ceará registra 2.957 suicídios em cinco anos. Disponível em http://diariodonordeste.verdesmares.com.br/cadernos/cidade/ceararegistra-2-957-suicidios-em-cinco-anos-1.1824235. Acesso em 29 out. 2017.

MARX, K. Sobre o suicídio. São Paulo: Boitempo, 2006.

NEVES, S.R.S. Suicídio e alienação: a vivência cotidiana da desigualdade e da exclusão social. 187f. Dissertação (Mestrado em Serviço Social), Universidade Federal do Pará, Belém, Pará, 2007. Disponível em http://ppgss.ufpa.br/arquivos/dissertacoes/2005/sandra_regina_smith_neves.pdf. Acesso em 11 jan. 2019.

PINHEIRO, I. S. A Intervenção do assistente social no atendimento de emergência do HU/UFSC às tentativas de suicídio. 78f. Trabalho de Conclusão de Curso (Graduação) Departamento de Serviço Social, Universidade Federal de Santa Catarina, Florianópolis, Santa Catarina, 2008. Disponível em

https://repositorio.ufsc.br/bitstream/handle/123456789/119346/287115.pdf?sequence=1\&isAl lowed=y. Acesso em 14 jan. 2019.

SANTOS, Aline Dias; NASCIMENTO, Luiza Queiroz do; ROSA, Tatiana Paiva. O Serviço Social no atendimento ao usuário vítima de tentativa de suicídio: desafios e possibilidades. 28f. Trabalho de Conclusão de Curso (Graduação) - Faculdade de Serviço Social, Escola Superior de Ciências da Santa Casa de Misericórdia de Vitória - EMESCAM, Vitória, Espírito Santo, 2016. Acesso em http://www.emescam.br/arquivos/TCCs/Servi\%C3\%A7o\%20Social/2016_2/04_Aliane_Luiza _Tatiana.pdf. Acesso em 14 jan. 2019. 
VELOSO, C. et al. Violência autoinfligida por intoxicação exógena em um serviço de urgência e emergência. Rev Gaúcha Enferm. 2017;38(2): e66187. Disponível em:

http://www.scielo.br/pdf/rgenf/v38n2/0102-6933-rgenf-1983-144720170266187.pdf. Acesso em 14 mai. 2018.

WORLD HEALT ORGANIZATION/ONU. Preventing suicide: a global imperative. 2014. 92p. Disponível em http://apps.who.int/iris/bitstream/10665/131056/1/9789241564779_eng.pdf?ua=1\&ua=1 . Acesso em 05 dez. 2017.

Data de recebimento: $11 / 01 / 2019$

Data de aceite: $13 / 11 / 2019$

\section{Sobre os autores:}

Francisco Elenilton Rodrigues do Nascimento é Graduado em Serviço Social pelo Universidade Estadual do Ceará (UECE). Especialista em Políticas Públicas, Gestão e Serviços Sociais pela Universidade Cândido Mendes (UCAM). Especialista em Saúde Mental pelo Programa de Residência Integrada Multiprofissional em Atenção Hospitalar à Saúde da Universidade Federal do Ceará (UFC). Endereço Eletrônico: elenilton_cot@hotmail.com

Maria Graça Fonseca Rocha é Assistente Social do Hospital Universitário Walter Cantídio (HUWC), Fortaleza/CE. Mestre em Avaliação de Políticas Públicas pela Universidade Federal do Ceará (UFC). Endereço Eletrônico: rochagraca@hotmail.com

Ana Paula de Lima Silva é Assistente Social do Hospital Universitário Walter Cantídio (HUWC), Fortaleza/CE e preceptora do Programa de Residência Integrada Multiprofissional em Atenção Hospitalar à Saúde da Universidade Federal do Ceará (UFC) com ênfase em Saúde Mental. Endereço Eletrônico: paula_dlsilva@yahoo.com.br 